\title{
Simulation Studies on the Non-uniform Temperature of Steel Members by the Solar Radiations
}

\author{
Li Jingfang ${ }^{1}$ and Jin Xiaofei ${ }^{2}$ \\ 1. China state construction technical center \\ 2. China construction first engineering division Corp Ltd. \\ Beijing, China \\ E-mail:jinxiaofei@cscec.com.cn
}

\author{
Li Xiaoye, Qian Hongliang and Chen You \\ Department of civil engineering, Harbin Institute of \\ Technology at Weihai \\ Weihai, China
}

\begin{abstract}
The thermodynamic analysis of long-span structure can be very complicated with the numerous members and high-degree indeterminate. In this paper, a typical spatial grid model with $4.5 \times 4.5$ meters plane is simulated, through the numerical simulation study on grid temperature field by solar radiation in winter and summer. The results show that: solar radiation can cause a non-uniform temperature field on grid model, of which the maximum temperature in summer is up to $52^{\circ} \mathrm{C}$, temperature rising is $20^{\circ} \mathrm{C}$, the maximum temperature difference among members is up to $14^{\circ} \mathrm{C}$, In winter the overall temperature of the component is low; The azimuth of the chords has little effect on the temperature change law, which has great influence on the change of the web member temperature.
\end{abstract}

Keywords-grid model; high-degree indeterminate; nonuniform temperature field; temperature difference; steel structure

\section{INTRODUCTION}

With the development of urban modernization and the increase of population, in order to meet the vast housing and site demand, the long-span, large-space, super-high have been a development direction of architectural construction. With huge geometric size, numerous members, complex structure, and high-degree indeterminate, the secondary thermal stress of space steel structure caused by redundant constraint can be very complicated. During the surface construction process, the non-uniformity solar temperature load takes an important part or even become the controlling factor in the structure design and closure processing [1].

The research on temperature effects on structure has some achievements since the problem raised up. However at present, the constructional code does not consider the role of nonuniform temperature effects. The analysis method in code gives a uniform temperature method with the use of the maximum, minimum, and the initial average temperature of structure determined by the theory of engineering thermodynamics, which is based on the mean monthly temperature 50-year recurrence interval[2]:

Present foreign scholars working on non-uniform temperature field analysis mainly focus on such structures like bridge[3-5], dam[6-7], radio telescope[8], and for special structure like stadiums, Exhibition Center and terminal space structure, experience is limited and further study is needed. As to domestic circumstance, tests and numerical simulations of

This work is supported by CSCEC Technical and Development plan (CSCEC-2012-Z-07) and Natural science fund projects (51378149). steel components are mainly research issues[9-13], but for scaled model there is almost blank. As stated previously, measurement and the accuracy verification of simulation method of spatial grid scaled model on the non-uniform temperature is of utmost importance.

In this paper, the experimental research focus on the nonuniform temperature field numerical simulation of the grid scaled model in summer and winter, and get the typical distribution law of them.

\section{THE NUMERICAL SimULATION}

\section{A. Finite Element Model}

According to the geometric dimension and material thermal physical properties of each component, as shown in Fig. 1, the finite element software ANSYS is adopted to establish the finite element model of the component temperature field, element list as shown in Table 1.

TABLE 1: ANSYS Simulation elements

\begin{tabular}{|c|c|}
\hline transfer type & ANSYS Simulation elements \\
\hline $\begin{array}{c}\text { Thermal } \\
\text { conduction. }\end{array}$ & SHELL57( 3 dimensional shell element) \\
\hline Thermal convection & SURF152(surface effect element) \\
\hline Thermal radiation & LINK31(3 dimensional two-node radiating \\
element)
\end{tabular}

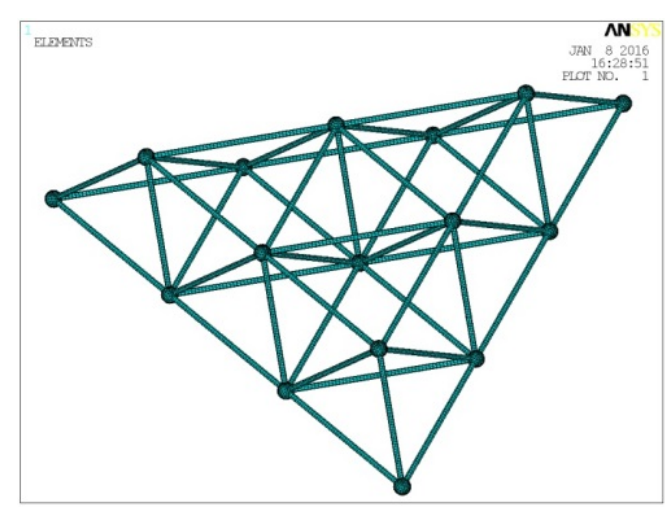

Fig. 1. Finite element model for thermal analysis 


\section{B. Solar Radiation Intensity}

Solar radiation intensity is the main heat load of the space structure under the sunlight. Chose Dilger model to calculate the solar radiation intensity, the formula is:

$$
S_{d}=0.90^{m p} J
$$

$\mathrm{J}$ : solar radiation intensity

m: Atmospheric optical quality modified by atmospheric pressure p: Atmospheric turbidity factor

Sun shading is an important factor affecting the distribution of direct solar radiation on the surface of the structure. For the grid model in this paper, the shadow is caused by two parts: the bar self-occlusion and that from other bars. For the self-occlusion, the judgment method is to judge the angle between the shell element normal and the sun ray vector. For the mutual occlusion, the ray-casting algorithm is adopted. The steps are as follows:

Step 1: In ANSYS software, the finite element model is established by the global coordinate system, and the element size must be small enough to get the accurate result.

Step 2: Transform the coordinates of the global coordinate system to the analytical coordinate system, make the $\mathrm{Z}$ axis parallel with the rays of the sun.

Step 3: Determine the sun ray equation by the azimuth angle and the solar altitude angle. The intersection points between the element central line equation and the projection plane ( $\mathrm{Z}=0$ plane) is created as the new nodes.

Step 4: For the area of shell element in projection surface, selected the new nodes created in step 3. Judge the element is occluded if $\mathrm{Z}$ coordinate is larger than that of new node of the shell element, then this unit is blocked, and vice versa.

Fig. 2 shows the shading distribution of the grid, the red represents the sun, blue represents the shadow area.

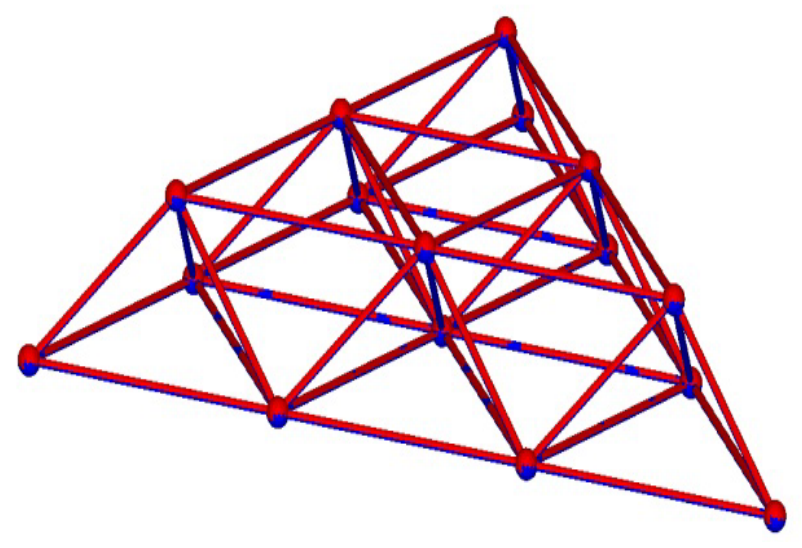

Fig. 2. Grid shading distribution layou

\section{Other Influence factors}

In this paper, to simulate the temperature condition in summer and winter, the summer solstice and winter solstice are chose as the typical data. The simulation parameters are shown in Table 2. Data in brackets is that of the winter solstice.

TABLE 2: Simulation parameters list

\begin{tabular}{|c|c|}
\hline parameters & Value \\
\hline The latitude & 36.5 north \\
\hline wind velocity & $1 \mathrm{~m} / \mathrm{s}(2 \mathrm{~m} / \mathrm{s})$ \\
\hline Surface albedo & 0.3 \\
\hline $\begin{array}{c}\text { temperature daily } \\
\text { change function }\end{array}$ & $\begin{array}{c}30.5+3.5 \sin (15 \mathrm{t}-105) \\
(6.5+3.5 \sin (15 \mathrm{t}-105))\end{array}$ \\
\hline Radiation absorption & $2(3)$ \\
\hline Atmospheric turbidity factor & $23.45(4.6)$ \\
\hline solar declination & $1416.58 \mathrm{~W} / \mathrm{m}^{2}$ \\
\hline solar radiation intensity & \\
\hline
\end{tabular}

\section{RESULTS AND ANALYSIS}

\section{A. Grid Temperature Field in Summerand Winter}

Fig. 3 and Fig. 4 shows the temperature field distribution of grid model at 11:00 14:00 in summer and winter, through which can be seen:

(1) The maximum temperature of members in summer appears at 12:00 and in winter the time is 13:00. The sun grid temperature field distribution is not uniform in both summer and winter and which is varying with time, the temperature difference between different members up to a maximum of $14^{\circ} \mathrm{C}$ in summer, $11^{\circ} \mathrm{C}$ in winter.

(2) Grid temperature maximum value appeared at the solder balls, which is due to the welding ball have larger section area. The followed are the outer rings of the bottom chords of which the second highest temperature is caused by the solar radiation reflected by the sun visors. The inner rings of bottom chords have lower temperature by the effect of occlusion. The temperature change curves are not same for the web members with different azimuth. When the angle between web member and solar radiation vector is larger, the temperature rise is higher. The more parallel between bars and sun rays, the lower temperature is. 


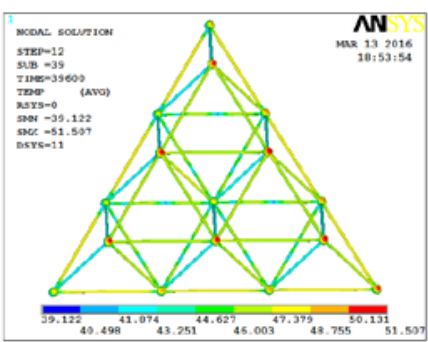

a) $11: 00$

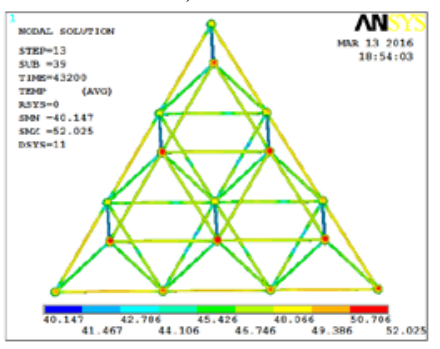

b) 12:00

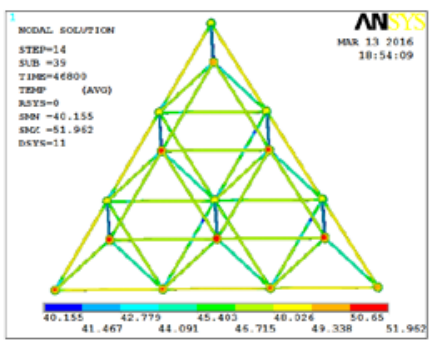

c) $13: 00$

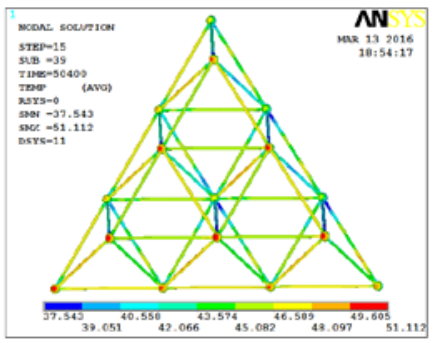

d) $14: 00$

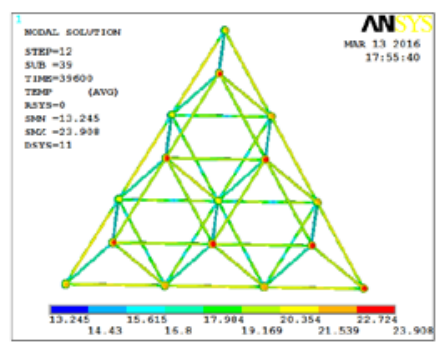

a) $11: 00$

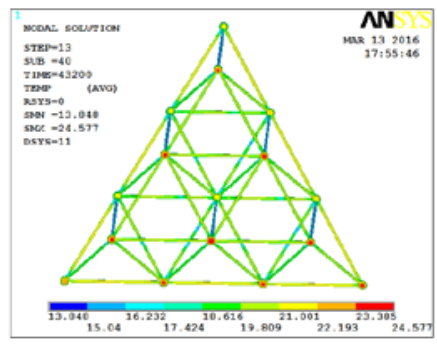

b) $12: 00$

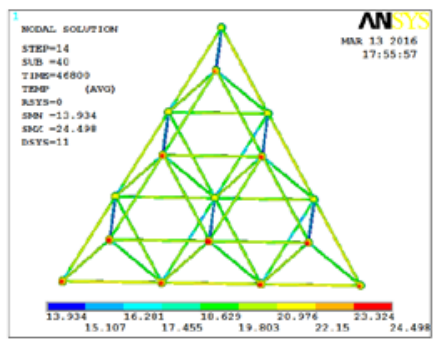

c) $13: 00$

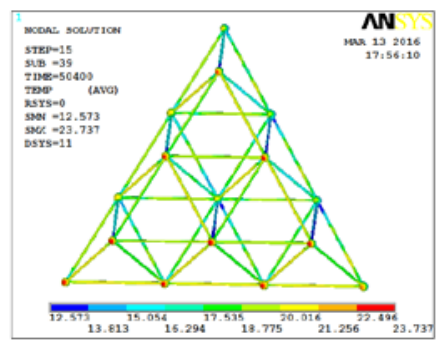

d) $14: 00$

Fig. 3. Grid temperature field patternFig. 4. Grid temperature field pattern in summer

in winter

Fig. 5 is the maximum and minimum temperature history curve of the grid in summer and winter, it tells that:

(1) The maximum and minimum temperature history curve is similar to sinusoid. In summer, the maximum temperature can reach to $52^{\circ} \mathrm{C}$ with maximum temperature rise $20^{\circ} \mathrm{C}$, the maximum temperature difference is $14^{\circ} \mathrm{C}$. In winter, the maximum temperature is $25^{\circ} \mathrm{C}$ with maximum temperature rise $15^{\circ} \mathrm{C}$, the maximum temperature difference is $11^{\circ} \mathrm{C}$.

(2) The maximum and minimum nocturnal grid temperature is both $2 \sim 3^{\circ} \mathrm{C}$ less than the atmospheric temperature which is decreased by the radiation heat transfer between members and ground; In winter the overall temperature of the component is low but the non-uniform temperature field is still obvious, which should be considered in the actual grid design work.

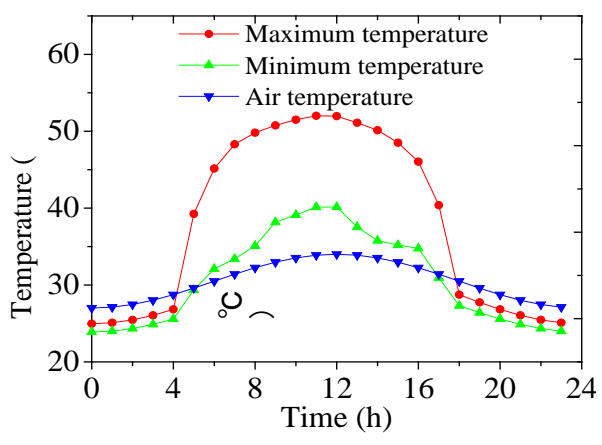

a) summer

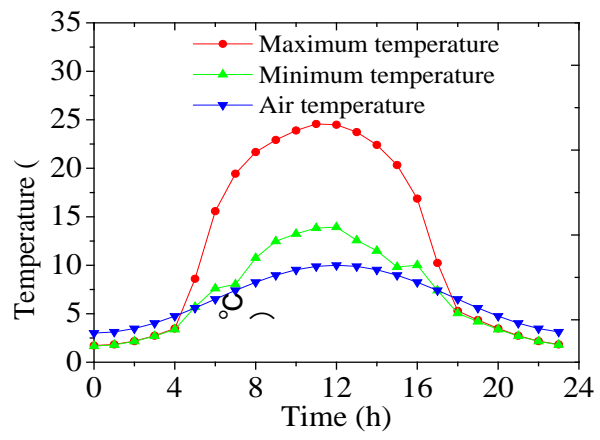

b) winter

Fig. 5. The maximum and minimum temperature history curve

\section{B. Member Azimuth Effect to Temperature Field}

One of the main factors that cause the uneven temperature field is the azimuth of the spatial structure member. In this paper, the temperature field of chord member and web member with the same and different azimuth are analyzed. Each of three elements of gird top chord, web member and bottom chord were extracted, The location of each element is shown in Fig. 6 , The definition of three elements of chord are T1, T2, $\mathrm{T} 3$, web members are $\mathrm{W} 1, \mathrm{~W} 2, \mathrm{~W} 3$, bottom chord are B1, B2, B3.

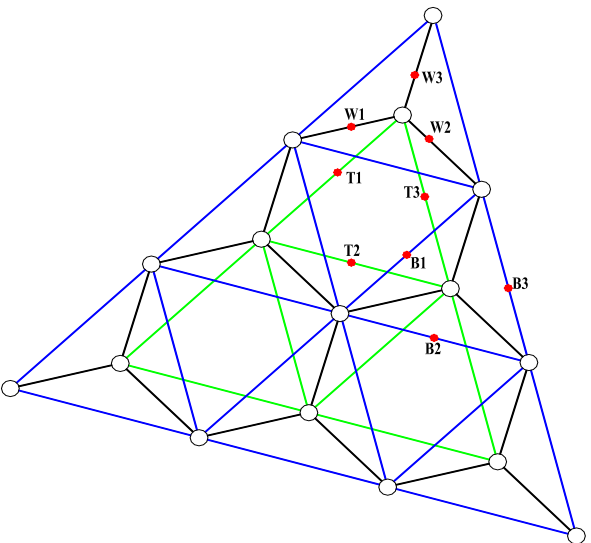

Fig. 6. Position of extraction elements

Fig. 7 shows the temperature rise curve of grid top chord and bottom chord with the different azimuth in summer, from which we can see: the temperature rise curve of measuring point put on top of the bar T1 T3, B1 B3 almost coincide with that of bottom side, except very individual difference 
more than $2^{\circ} \mathrm{C}$, the temperature difference of rest bars with different azimuth is all less than $2^{\circ} \mathrm{C}$. So that leads us to the conclusion that: to the structure member at the same height and same plane but with different azimuth, the temperature regularities are the same.

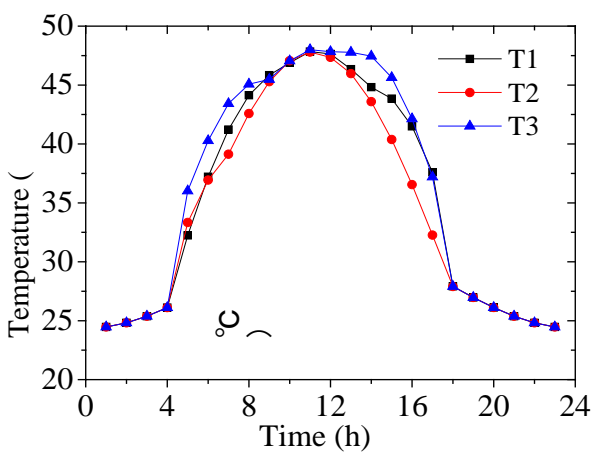

a) Top chord

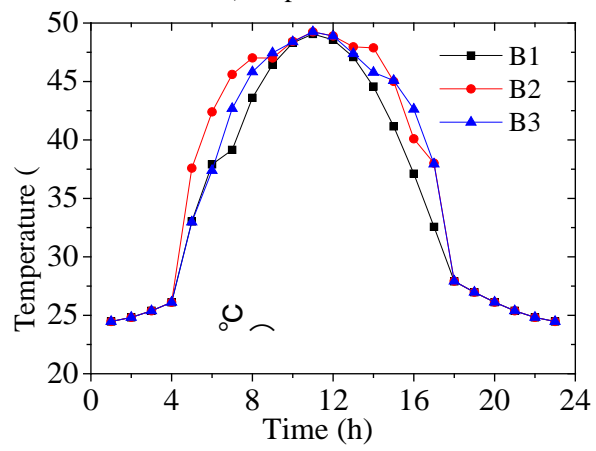

b) Bottom chord

Fig. 7. Chord Members temperature time history curve

Fig. 8 is the comparison temperature rise curve of bars with different azimuth, it tells that: web members with different azimuth have different temperature change law and nonuniform temperature field exist during different time of which the highest difference reach to $12^{\circ} \mathrm{C}$.

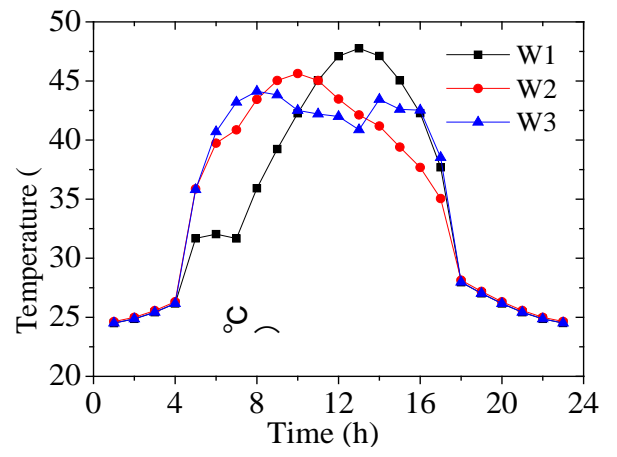

Fig. 8. Web Members temperature time history curve

\section{CONCLUSION}

In this paper, through the numerical simulation study on grid temperature field by solar radiation in winter and summer, we get the following conclusions:

The grid model has Non-uniform temperature field under sunlight, and the maximum temperature of member in summer can reach to $52^{\circ} \mathrm{C}$ with the temperature rise $20^{\circ} \mathrm{C}$, the maximum temperature difference $14^{\circ} \mathrm{C}$. In winter the overall temperature of the component is low but the maximum temperature difference can reach to $11^{\circ} \mathrm{C}$, which also should be considered in the actual grid design work; the azimuth of the chords has little effect on the temperature change law, which has great influence on the change of the web member temperature.

\section{REFERENCES}

[1] Fan Zhong.Wang Zhe.Tang Jie, "Analysis on temperature field and determination of temperature upon healingof large-span steel structure of the National Stadium,” Journal of Building Structures, vol. 28, pp. 32-40, April 2007 (In Chinese).

[2] Load code for the design of building structures, China Architecture \& Building Press. 2012, pp. 64-65.

[3] Tong M.Tham LG,Au F. K, "Numerical Modeling for Temperature Distribution in Steel Bridges," Computers andStructures, vol. 79, pp. 583-593, May 2000.

[4] KIM S H,CHO K-I,WON J. H, "A Study on ThermalBehavior of Curved Steel Box Girder Bridges Considering Solar R adiation,” Archives of Civil and Mechanical Engineering, vol. 9, pp. 59-76, July 2009

[5] Xu Y L,Chen B,Ng C L,et al, "Monitoring Temperature Effect on a Long Suspension Bridge,” Structural Control and Health Monitoring, vol. 17, pp. 632-653, March 2010.

[6] Jin Feng,Chen Zheng,Wang Jinting,et al, "Practical Procedure for Predicting Non-Uniform Temperature on the Exposed Face of Arch Dams,” Applied Thermal Engineering, vol. 20, pp. 2146-2156, September 2010 (In Chinese).

[7] Noorzaei J,Bayagoob K H,Thanoon W A,et al, “Thermal and Stress Analysis of Kinta RCC Dam,” Engineering Structures, vol. 28, pp. 1795-1802, August 2006.

[8] Von Hoerner.S, “Design of large steerable antennas,” the Astro, vol. 72, pp. 35, June 1967.

[9] Zeng Zhibin,Zhang Yuling, "Stress monitoring of the large-span steel structure of the $\mathrm{N}$ ational Stadium during unloading," China Civil Engineering Journal, vol. 41, pp. 1-6, March 2008 (In Chinese).

[10] Guo Yanlin,Tian Guangyu,Liu Xuewu, "Influence of Temperature Change on Closure Process of the Cantilever of New CCTV Headquarters,” Construction Technology, vol. 37, pp. 1-8, May 2008 (In Chinese).

[11] Xie Guoang,Fu Xueyi,et,al, “Construction simulation analysis of steel structure for National Swimming Center," Journal of Building Structures, vol. 30, pp. 142-147, December 2009 (In Chinese).

[12] Lin Cuocuo,Wang Yuanqing,Shi Yongjiu, "Analysis of the temperature field of steel members in sunshine,” Journal of steel structure, vol. 25, pp. 39-43, May 2010 (In Chinese).

[13] Liu Hongbo,Chen Zhihua,Wang xiaodun, "Temperature effect of suspendome with stacked arch structure considering solar radiation," Journal of Tianjin University, vol. 43, pp. 705-710, August 2010 (In Chinese). 